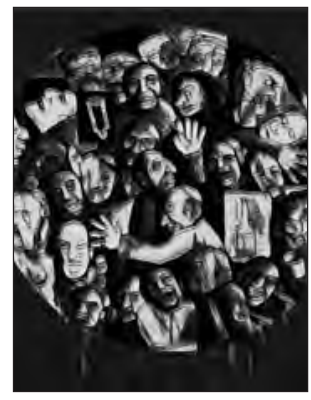

\title{
EL LUGAR DE LA
}

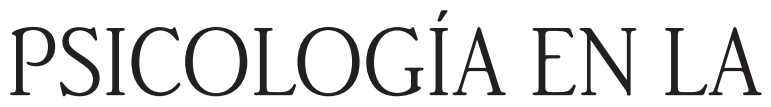

FILOSOFÍA DE LA EDUCACIÓN:

\section{SUPERANDO LA VISIÓN BEHAVIORISTA DE LA PSICOLOGİA}

Dra. Ximena Andrade

Psicóloga clínica

Universidad Politécnica Salesiana

Diplomada en docencia universitaria 


\title{
Introducción
}

La relación entre filosofía, pedagogía y psicología ha sido y sigue siendo debatida, sobre todo parece ser que el vínculo con la psicología resulta menos legible entre quienes hacen filosofía dando lugar a inquietudes como: ¿tiene cabida la psicología en la Filosofía de la Educación? ¿Cuál es el lugar que ocupa? Interrogantes que permiten evidenciar la duda sobre el aporte que esta ciencia puede brindar en este campo, entonces, por qué relacionarlas? Precisamente este artículo se orienta a brindar aportes para la reflexión, como escenario que permitirá al lector construir la respuesta a estas inquietudes a partir del análisis de diversas temáticas que se interrelacionan, tener claro que resulta absurdo la formación del filósofo de la educación desligado de la comprensión del comportamiento desde una perspectiva científica del actor que posibilita el hcho educativo "el ser humano" y, visualizar la identidad que distingue a la filosofía de la educación, claro que en esta ocasión desde la mirada de la psicología y en relación con ella.

\section{Educación, psique y contexto mundial}

\author{
"Las cosas se han subido a la silla y cabalgan \\ sobre la humanidad" \\ Emerson
}

Hablar de Filosofía de la Educación, nos sumerge en un hecho tan delicado como humano, "el educativo". El aporte del filósofo de la Educación, desde mi entender, debe orientarse al planteamiento de elementos que permitan reflexionar este campo, entendido como un acto netamente humano, de tal manera que pueda vincularse y responder a las necesidades que la sociedad presenta y a 
las que será necesario crearlas ${ }^{1}$ y/o recrearlas para propiciar su transformación.

Nadie duda que para hacerle frente a los nuevos retos del actual contexto mundial, sea adaptándose o resistiéndose, la educación (formal y no formal) es un campo estratégico, por tanto, no solo para los soñadores, sensibles, críticos y utópicos seres humanos que quieren resistirse a la corriente en la que intenta y/o sumerge el mundo globalizado y neoliberalmente ideologizado, sino, que paradójicamente, también para las visiones hegemónicas, quienes hasta el momento le han sacado mayor provecho al hecho educativo que por su naturaleza cala en la subjetividad de las personas y por tanto se han valido de él para apuntalar las actuales condiciones sociales.

Así, la educación, está muy lejos de ser un hecho neutral, sin direccionalidad, intencionalidad e influencia en el comportamiento individual y colectivo, claro está que esa intencionalidad, direccionalidad e influencia depende de la ideología con la que es asumida y trabajada. Así, en líneas anteriores afirmaba que se constituye en campo estratégico, logrando el sistema neoliberal calar profundamente en el psiquismo de los sujetos generando comportamientos que lo sostienen y que se reproducen en la cotidianidad.

Somos protagonistas y lectores de una realidad que lacera la construcción saludable de la personalidad, siendo en muchos casos lo que podemos ser y no lo que queremos ser, construyendo en el individuo, de forma perversa, el imaginario de libertad y respeto a la individualidad, en una sociedad en donde se nos permite movernos con "libertad" hasta los límites donde no se afecte el orden social establecido.

En el actual contexto mundial, el ser humano es prioridad en la medida en que dinamiza y sostiene la cul- 
tura de mercado y para ello se lo prepara, pero aún en este caso es la lógica del mercado quien le permite ubicarse como un ser de prioridad, en tanto y cuanto funcione para ella, es decir su sola condición de humano no le garantiza ese privilegio, construyéndose desde este contexto subjetividades alienadas y por tanto deshumanizadas, encontrándonos en el diario vivir con muestras abundantes de egoísmo, explotación, desconfianza, corrupción y peor aún de intensa desilusión y desesperanza que raya en la diselpidia ${ }^{2}$, siendo éstas, algunas de las secuelas que produce el neoliberalismo al penetrar en la profundidad del psiquismo, configurando nuevas formas de comportarse, que en términos de Rebellato, son el resultado de la capacidad que poseen los modelos neoliberales para "penetrar y moldear el imaginario social, la vida cotidiana, los valores que orientan nuestros comportamientos en la sociedad"3.

La educación en el término más amplio y la de tipo formal de manera más específica se constituye en el camino elegido para configurar subjetividades adaptables al sistema, parafraseando a Habermas, dando lugar a subjetividades colonizadas, y con ello también a la manifestación de nuevas patologías psíquicas, que lamentablemente por estar tan ancladas en la cotidianidad son asumidas como "naturales" constituyéndose en lo que Fromm plantea como defecto socialmente modelado o en sus propios términos validado consensualmente y expone:

"Hoy nos encontramos con personas que obran y sienten como si fueran autómatas; que no experimentan nunca nada que sea verdaderamente suyo; que se sienten a sí mismas tal como creen que se las considera; cuya sonrisa artificial ha reemplazado a la verdadera risa; cuya charla insignificante ha sustituido al lenguaje comunicativo; cu- 
ya sorda desesperanza ha tomado el lugar del dolor auténtico. De esas personas puede afirmarse dos cosas.

Una es que padecen un defecto de espontaneidad e individualidad que puede considerarse incurable. Al mismo tiempo, puede decirse que no difiere en esencia de millones de otras personas que están en la misma situación. La cultura les proporciona a la mayor parte de ellas normas que les permiten vivir con un defecto sin enfermarse. Es como si cada cultura proporcionara el remedio contra la exteriorización de síntomas neuróticos manifiestos que son resultantes del defecto que ella misma produce"4.

Este breve párrafo de un interesante y extenso análisis que realiza el autor sobre el defecto socialmente modelado en relación con la salud mental, resulta oportuno y aún vigente a pesar de haber transcurrido alrededor de 50 años de haber sido planteado, pues podemos evidenciar que vivimos una sociedad que se ha encargado de producir patologías socialmente aceptables o por lo menos defectos que ya no molestan, ya no incomodan, ya no interpelan, ni a los individuos ni a la sociedad que la conforman, (al menos no a la mayoría) llegando entonces a primar uno de los criterios que aplicado a la salud mental es considerado desde posturas críticas, atomista y hasta peligroso, como es el criterio estadístico, en el que se plantea que patología se podría considerar exclusivamente a la manifestación que se desvía del promedio, de la norma; en otras palabras, si la mayoría presenta un síntoma o patología, ésta se anula o se convierte en un malestar que no perturba e incluso en un referente en la construcción de subjetividades; así, por ejemplo, la codicia, la competencia desleal, la carrera por alcanzar el "éxito" en términos económicos en detrimento de los afectos y lazos familiares, la 
rivalidad, el individualismo, etc, se manifiestan en forma cotidiana en los diferentes estilos de vida y se propician como manifestaciones saludables del perfil de las personas que el mundo actual en su mayoría requiere, es decir "personas competitivas".

Las nuevas patologías se evidencian también (a pesar de que lo expuesto en líneas anteriores ya es violento) a través de la llamada "cultura de violencia". La caricia, que al tener la connotación de "invasiva" en tanto no deseada, se torna violenta y maltratante (el beso "robado" a un niño o niña en contra de su voluntad, como ejemplo más benévolo), en ubicar al otro como sujeto de burla, en la exclusión, pero también en la reclusión; es decir, para los que están en la vereda de enfrente, esa minoría no excluida económicamente hablando, pero que no puede vivir con libertad, al menos no con la libertad que da la interacción humana espontánea, porque su posición de privilegiado le hace sentirse constantemente amenazado; así pues, viven una reclusión para privilegiar o salvaguardar sus bienes. Por ello Ferrara plantea que la tensión no es ya exclusión-inclusión, sino exclusión-reclusión, siendo ambas resultado de la violencia social, la misma que se manifiesta hasta en los actos aparentemente "bien intencionados" como el educativo: al estigmatizar, al "educar" sobre la base del miedo y la culpa, generando sumisión como manifestación del poder y la autoridad que se estructura en toda relación humana $y$, muy evidentemente en la mayoría de relaciones en el campo educativo, dejando en muchas ocasiones huellas dolorosas en el proceso de formación de la personalidad, como es el caso de la educación tradicional, que por su naturaleza es violenta por que se sustenta en la "enseñanza" jerarquizada, basada en el miedo como ejercicio de un poder mal entendido. 
Así, el miedo, deja de ser esa alarma natural que posee el ser humano para actuar frente al peligro, para convertirse en forma cotidiana de actuar, cuya implicación más dolorosa es la sumisión y el control; por tanto, la educación, si se la puede llamar así o talvez es más apropiado hablar de instrucción basada en el miedo y que no es cosa del pasado sino que se manifiesta actualmente, construyendo subjetividades enajenadas, pues al ser el miedo una expresión emocional y de acuerdo a la intensidad con la que se manifiesta, bloquea los procesos intelectuales, lo que a su vez profundiza la estigmatización al estudiante y nuevamente se expresa la violencia como manifestación de poder, tornándose un círculo vicioso mediado y sustentado por el silencio. "El miedo congrega una multitud de sentires que finalmente encierran al ser humano en sí mismo, limitando o paralizando su capacidad de acción"5, acción que no solo tiene connotaciones individuales sino sociales; así, las secuelas de la represión rebasan los límites del aula y al penetrar en la subjetividad de las personas desde la infancia, etapa evolutivamente clave, en la conformación de la personalidad, el miedo se enraíza en el psiquismo y se expresa en las formas de ser y hacer de las personas; así, la represión ha hecho un buen trabajo, minando la actoría social de los sujetos que ante el miedo hecho carne, se ha tornado pasivo y conformista, lo que ratifica que la educación no es un acto neutral.

Es posible entonces, que el miedo se haya convertido en otro defecto socialmente modelado; la exclusión construye miedos: a no ser aceptado socialmente, a no sobrevivir, a no triunfar, entre otros, pero también la reclusión genera miedos: a ser atacado, a ser perseguido, a ser invadido, a ser despojado de sus bienes e incluso a la interacción humana. 
La competitividad es entonces miedo al fracaso; el individualismo es entonces miedo al otro o a lo que el otro puede hacer mejor que nosotros; la cultura del silencio no es más que otra manifestación del miedo.

El miedo es entonces una construcción de la violencia, pero también violencia en sí mismo; una educación sobre esta base, no es otra cosa que un acto de humillación en oposición a lo que debe ser la educación y que muy claramente lo propone Daniel Prieto Castillo ¡un acto de dignidad!.

La violencia se manifiesta en la cotidianidad del mundo globalizado, como expresión de la competitividad, pues como manifiesta Rebellato, "se pierde el valor del otro como alteridad dialogante y se lo reemplaza por el valor del otro como alteridad amenazante: "sólo los paranoicos sobrevivirán", dicen los neoliberales (queriendo referirse al hecho de que en el mercado, sólo quien ve a los demás como amenazas, puede competir)"6.

Sentencia digna de resistencia: "El hecho de que millones de personas compartan los mismos vicios no convierten esos vicios en virtudes; el hecho de que compartan muchos errores no convierten a éstos en verdades; y el hecho de que millones de personas padezcan las mismas formas de patología mental, no hace de esas personas gentes equilibradas" 7 .

Esta es la reflexión a la que pretende contribuir la psicología en relación al campo educativo, pues el ser humano es un ser complejo bio-psico-socio-cultural y es necesario conocer sus múltiples dimensiones, ya que el acto educativo afecta a cada una de ellas. La educación no es atemporal, pues responde a un momento histórico determinado, es por ello que no se puede obviar la actual realidad mundial y sus consecuencias para analizar la educación, pues este contexto determi- 
na lo que muchos autores llaman la construcción de nuevas subjetividades, vinculado por tanto a la salud mental de los involucrados.

En medio de esta realidad afortunadamente hay esperanza para crear, para transformar, para compartir, para confiar, para construir subjetividades humanizadas en oposición a las amenazadas; y es también el campo educativo, nuevamente, la estrategia, pero desde una visión antihegemónica, crítica, solidaria, desde una educación renovada y promotora de salud mental, una educación que priorice al ser humano y le devuelva la dignidad y la confianza en los demás, una educación que nos libere de miedos y por tanto de culpas, pero no de responsabilidades, sobre todo, la de construir un proyecto saludable y solidario de vida, una educación posicionada políticamente en oposición a una educación funcional, utilitaria y por tanto a-crítica.

"Estamos en el terreno de un proyecto pedagógico. Toda asignatura, toda carrera, toda facultad, toda institución universitaria, debería serlo. Proyecto en acto, no en aspiraciones expresadas en las capacidades volcadas a borbotones a la hora de presentar el perfil del egresado. Proyecto en acto significa prever los conceptos y las prácticas de aprendizaje que les darán algún sentido. Maravilloso saber; y ahora ¿qué hago con él? Los educadores tenemos el derecho a lograr con nuestros estudiantes experiencias pedagógicas decisivas, entendidas, como un profundo encuentro entre seres humanos que arrojan resultados de aprendizaje ricos en producción intelectual y en crecimiento personal"s

Si he planteado la relación educación y salud mental, no puedo dejar de hacer referencia a la afectividad. Existe la necesidad de contribuir para desarrollar una educación que promueva la manifestación de los afectos, que permita su expresión y además podamos respetar la 
de los demás; una educación que nos enseñe a leer y escribir las palabras pero que no nos convierta en analfabetos de los sentimientos, una educación por tanto que despierte la sensibilidad, que nos duela el dolor propio y ajeno, sin que eso signifique desesperanza, que no nos lleve a ocultar lo que sentimos y a ser seres indiferentes. Una educación que permita recuperar la estima no solo en relación con los estudiantes, sino también la del educador, una educación sensible y humana.

Una educación que no promueva la violencia, la corrupción, sino el respeto en la relación interpersonal.

Una educación que nos enseñe a enfrentar las dificultades, a posicionarnos frente a los retos, que nos permita aprender de los errores, que parta de la aceptación del otro, una educación que promueva la construcción de personalidades saludables, que sea parte de la construcción de auto conceptos positivos, que se refleje en seres humanos que se saben capaces, útiles, fraternos.

La especie humana supo crear la ciencia y el arte: ¿por qué no ha de ser capaz de crear un mundo de justicia, fraternidad y paz? La especie humana ha producido a Platón, Homero, Shakespeare y Hugo, Miguel Angel y Beethoven,Pascal y Newton, héroes humanos todos cuyo genio no es más que el contacto con las verdades fundamentales, con la esencia recóndita del universo. ¿Por qué no ha de poder la misma especie producir directores capaces de conducirla a aquellas formas de vida en común más próximas a las vidas y la armonía del universo?

Léon Blum.

Entonces, podríamos también decir que, si la educación desde la ideología dominante, ha tenido la ca- 
pacidad de promover el deterioro de la salud mental, ¿por qué no ha de poder la misma educación desde una mirada humanizada y humanizante (antihegemónica), preservarla y fomentarla?

El reto está planteado; la psicología, por tanto, no está divorciada del proceso educativo pues he analizado cómo éste implica construcción y manifestación de subjetividades e inter-subjetividades. ¿Cómo podemos entonces pensar la educación, si desconocemos los elementos psicológicos que en ella se ponen en juego? Conocimiento entonces que se justifica, para hacer del proceso educativo un espacio de permanente reflexión desde una mirada interdisciplinaria.

\section{Aporte de la psicología a la filosofía de la educación}

Si se ha planteado que la educación es una opción política, por lo que es necesario posicionarse frente a él, tampoco es posible asumir la psicología indiscriminadamente, pues también es necesario un posicionamiento frente a ella, que permita contribuir a la formación del filósofo de la educación como un profesional crítico y sensible ante el hecho educativo.

Los ámbitos de la escuela y del aula, muy a nuestro pesar no han sido y no son al menos en la mayor parte de instituciones educativas, los espacios de desarrollo integral, saludable, propiciador de aventuras creativas, de autenticidades, al menos no en sí mismos; si esto se ha desarrollado en ciertos estudiantes ha sido como producto de su propia capacidad de resistir las frustraciones, antes que por méritos del proceso educativo, constituyéndose entonces en espacios que propician, mantienen o desencadenan psicopatologías, pues como 
dice Clemencia Baraldi para que un sujeto este fuera del mundo "solo basta expulsarlo del campo de la cultura o someterlo compulsivamente a él" ${ }^{9}$, las experiencias educativas por tanto se convierten en experiencias de vida y dan forma a nuestra personalidad; sin embargo, este aspecto es subordinado a favor del conocimiento o más específicamente del aprendizaje que se constituye en el factor de enlace o "vertiente subjetiva por el que el ser humano se instala en este campo llamado de la Educación" 10 . No es mayormente preocupante que progresivamente se desmorone la estima personal de un estudiante, pero sí lo es si no alcanza el rendimiento académico promedio, entonces es común pensar que presenta algún "trastorno de aprendizaje" (es decir es un problema del Otro) lo que le libera al docente de responsabilidad, en una tendencia cotidiana a realizar atribuciones externas y no a enfrentar el reto educativo en su complejidad y, de esta manera, el síntoma se tornó en problema y las implicaciones más profundas quedan anuladas.

Por estas razones es necesario y responsable el estudio de la psicología desde una opción de superación de visiones funcionales, para lo cual el eje psicológico permite la familiarización con diversas visiones, no de manera ecléctica sino holística para propiciar en el estudiante una visión crítica del aporte psicológico.

Para clarificar lo dicho es necesario introducirnos en un breve análisis de los principales enfoques psicológicos y autores que permiten identificar el aporte de la psicología como disciplina científica a la filosofía de la educación, desde una opción que se orienta por la construcción de una educación antihegemónica y por tanto humana.

Los enfoques que a continuación se presentan y de los cuales se extraerán algunos postulados generales y 
se analizará su relación con el ámbito educativo, no han sido elegidos al asar, sino por ser grandes referentes psicológicos de los que es necesario identificar los pros y contras que ofrecen en su relación con la filosofía de la educación.

\section{El Conductismo}

Este sistema psicológico, como es conocido, responde muy bien a la visión positivista de la ciencia, centra su objeto de estudio en la conducta por considerar que le concede a la psicología la categoría de ciencia al ser objetiva, observable, experimentable y hasta cuantificable. Para esta visión la conducta no es más que la respuesta a los estímulos ambientales lo que permite entender por qué sus concepciones teóricas las elabora a partir del binomio clave E-R; todo lo que no responde al terreno de la objetividad queda desplazado de la concepción behaviorista como objeto de estudio, desinteresándose así de la dimensión afectiva y cognitiva, aspectos que ya en párrafos anteriores analicé su importancia como eje fundamental de la comprensión psíquica, pues no considerarlos equivale simbólicamente a mirar al ser humano con cuerpo pero sin cabeza y sin corazón diría alguien más.

Es propio del ambiente educativo hablar de "aprendizaje"11, término que tiene fuerte connotación conductista; casi todas las teorías que lo explican provienen de dicha corriente. Esto lleva a analizar las implicaciones que tiene. Así, desde esta concepción, constituye un proceso no mediado por la cognición y factible de construirse de forma idéntica tanto en los animales como en los seres humanos, pues es el resultado exclusivo de la manipulación externa, sea por la selección de los estímulos, la introducción de refuerzos o la elección y presentación 
de modelos que facilitan la construcción de aprendizajes que serán visualizados en la conducta, pues es lo que se puede evidenciar desde Watson hasta Bandura, reflejando el conductismo una cómoda forma de hacer ciencia "Prefería por una parte, la exactitud de lo manifestable y por otra, la operatividad de lo modificable, manipulando el ambiente exterior" 12 pero también al ser humano. Aquí radica una de las fuertes críticas que ha recibido esta visión pues es claro el denominado "peligro behaviorista" porque anula las libertades individuales y la posibilidad de concebir al ser humano más allá del mecanicismo, como un ser creativo, constructor y cognoscente. El peligro se instaura, además, en el énfasis que le da al desarrollo de la motivación extrínseca en menosprecio de la intrínseca, que es hacia donde debe apuntar el proceso educativo renovador. "El refuerzo constituye el núcleo de las técnicas de la modificación de conducta y, por lo mismo de las aportaciones más importantes que el modelo conductual proporciona a la educación"13.

No se trata de reducir a nada la visión conductista, es decir, anular algunas de sus propuestas como las del refuerzo que Hernández resalta como positivo, pues éste es entendido como la posibilidad de incrementar o instaurar una repuesta deseada; pero sí, de advertir que no es ni la única, ni la más saludable manera de construir aprendizajes y de forma más trascendente, conocimientos y saberes, pues excluye el uso de funciones psicológicas importantes como la voluntad, afectividad, pensamiento y mecaniza, centralizando la capacidad de generar aprendizaje o cambios en el agente externo (sujeto manipulador) y no en el sujeto que aprende; por ello no es casual que esta visión defina a la psicología como la ciencia que permite predecir y controlar la conducta, pues ¿quién garantiza que lo que un individuo se proponga hacer de otro 
sea saludable?; es entonces donde esta visión debe ser mirada críticamente para superar la tendencia funcionalista, dominante, utilitaria y pragmática que aun predomina en la educación, si queremos ser sujetos que aportan a la transformación de un contexto que no responde a las necesidades de las personas en términos humanos sino exclusivamente económicos, pues al sistema dominante le interesa modelos como éstos que les permita adiestrar y por tanto controlar la psiquis de los sujetos.

"Si la planificación de la enseñanza -concretamente la determinación de los objetivos instruccionales y el análisis de la tarea -, representa la actividad preliminar, y la evaluación la actividad postrera, el control de los antecedentes y consecuentes de la conducta del alumno, en cambio, constituye la actividad central del proceso didáctico.

El control del refuerzo por parte del profesor es la operación que puede proporcionar un incremento de las conductas deseables y un decremento de las no deseables. Se entiende por conducta tanto el comportamiento social como la ejecución de habilidades psicomotrices y cognoscitivas.

En la intervención psicoeducativa, la tarea primordial consiste en precisar cómo utilizar los refuerzos. Previamente deben determinarse los tipos de refuerzos, e incluso esclarecer qué es lo que se entiende por refuerzo" 14 .

Esta es una propuesta para ser aplicada en el trabajo pedagógico que la encontramos en un texto de psicología de la educación, y que es la tendencia de otros tantos, como si adiestramiento fuera el sinónimo de educación. Por el contrario, ésta debe propender a la construcción de 
seres humanos creativos, afectivos, con voluntad propia y concientes de su realidad; es decir, pasar de una visión netamente instruccional a una propuesta verdaderamente educativa, que se sustente en el aporte psicológico sí, pero desde una visión que supere los atomismos.

Generar procesos de aprendizaje donde primen las accione manipuladoras y controladoras para lograr el objetivo que la sociedad desde una visión dominante tinosamente quiere alcanzar al introducirse fuertemente en los diversos aspectos que componen el acto educativo es contribuir a la construcción de seres humanos inauténticos, manipulados y con tendencia a manipular, inseguros, controlados y por tanto coartados en su libertad.

\section{Psicología cognitiva}

Para la psicología cognitiva la conducta deja de ser el punto de referencia para centrarse en la actividad, lo que permite asumir al individuo constructor, influido e influyente. Para entender esta visión analizaré básicamente a dos autores que han tenido trascendencia y que desde enfoques diferentes le dieron un giro al acto pedagógico como son Jean Piaget y su epistemología genética y Lev Vygotsky y su teoría histórico- cultural, para ambos según afirma Sánchez-Barranco Ruiz, el pensamiento y el lenguaje ocupan un lugar de privilegio generando desde enfoques diferentes, un giro en la concepción pedagógica.

\section{Jean Piaget}

Biólogo y epistemólogo, representante de la denominada "epistemología genética", su teoría se centra en explicar el desarrollo del pensamiento lógico; para ello, manifiesta que deben considerarse tres influencias básicas: 
La maduración: "la aparición de los cambios biológicos que están genéticamente determinados en cada ser humano desde la concepción"15, es decir el pensamiento surge en la medida en que existe un proceso biológico que alcanza niveles complejos de funcionalidad, no puede existir desarrollo del pensamiento sin un mínimo nivel de madurez en relación al período evolutivo por el que cursa el individuo.

La actividad: la madurez física, facilita el despliegue de actividad del sujeto en el entorno, para Piaget, la actividad es importante ya que permite que el niño explore su entorno lo que influirá en el desarrollo cognitivo, esto facilita identificar la trascendencia en la propuesta de Piaget al señalar que es esta actividad exploratoria la que le permite construir el conocimiento.

La transmisión social: que permite aprender de los demás, es decir plantea que el desarrollo cognitivo no es exclusivamente un acto biológico, sino también social; aunque no haya dejado de reconocer este factor, no lo prioriza en su explicación de la construcción del pensamiento como es el caso de la teoría de Vygotsky. Estas influencias trabajan simultáneamente para incidir en el desarrollo cognoscitivo, sin que una de ellas tenga primacía sobre la otra.

Para Piaget el objetivo clave de la inteligencia es permitir la adaptación, la misma que se logra a partir de los procesos de asimilación y acomodación. En el primero la nueva información se ajusta a los esquemas mentales existente, para luego realizar el segundo proceso que implica modificar o ampliar los esquemas previamente establecidos para dar lugar a un nuevo conocimiento.

Otro análisis clave que realizó Piaget fue en relación al concepto de equilibrio que se define como "la 
búsqueda del balance mental entre los esquemas cognoscitivos y la información del medio"16; "es la acción que el sujeto realiza para compensar las perturbaciones ocasionadas por el entorno"17; el valor sustancial de este proceso de equilibración está en que al lograrlo, el conocimiento se construye y/o se transforma; por tanto, ha surgido un nuevo momento con mayor desarrollo cognitivo en relación a lo que sucedía en el momento previo al desequilibrio, ya que el equilibrio no es entendido como la vuelta al estado previo a la perturbación sino que se convierte en un equilibrio más complejo o superior. Para autores que han analizado la teoría de Piaget, como Fernández, Craig, Prieto Castillo, entre otros, este proceso de búsqueda del balance es lo que explica los cambios en la cognición. Así, "Piaget asumió que las personas continuamente ponen a prueba lo adecuado de sus procesos de pensamiento para lograr ese balance"18.

Los análisis de Daniel Prieto son muy clarificadores en relación al proceso de equilibración por lo que es necesario acudir a una parte de ellos:

"Nos interesa ver que el sujeto busca la equilibración, la que es cada vez más móvil. Esto nos indica cual es el rol del entorno, algo muy importante porque, cuando hablamos de educación, nos estamos refiriendo a una acción del entorno. Para Piaget, el entorno no figura sino como un "objeto de conquista", pero que no tiene un rol de causalidad formadora. Por lo tanto el medio (y la educación en consecuencia) no es causa de la forma que toma el desarrollo cognitivo, es decir, no determina el cómo transcurre el proceso de desarrollo cognitivo. Solo tiene un rol de servir como objeto de conquista, es decir obliga al individuo a una acción de conquista, y es esta acción la que va a desarrollar al sujeto" 19 . 
Este constituye un planteamiento innovador para la educación, pues permite considerar al sujeto constructor de sus capacidades cognitivas y no mero sujeto asimilador y reproductor, de aquí la necesidad de que el sujeto explore el medio y actúe sobre él.

Piaget plantea que el desarrollo cognitivo pasa por 4 etapas, en las que se visualiza su esfuerzo por explicar la psicogénesis de la inteligencia humana como "un proceso -como a él le gustaba decir- endógeno, natural y espontáneo en el sujeto"20.

Así lo entiende también Hernández "El pensamiento no es innato y tampoco se modela pasivamente con la influencia de los estímulos ambientales. Se construye, lo elabora el sujeto en su relación con el mundo"21; planteamiento que se opone a la visión conductual de aprendizaje no solo en su concepción, sino también en su intencionalidad, pues como afirma Baraldi: "Como se ejerce la práctica deviene de cómo y desde dónde se la conceptualiza" 22 .

Piaget ha permitido visualizar otra forma de construcción del conocimiento más respetuosa del ser humano, procesual y activa que permitió entender que el pensamiento del niño "tiene diversas fases y que es distinto del pensamiento adulto, ya que se sigue por principios y regulaciones especiales" 23 .

Las aplicaciones de la teoría de Piaget que pueden realizarse al campo psicoeducativo, constituye otro de sus aportes, aunque hay que aclarar que no fue su intencionalidad. "Para el autor, los conocimientos que la psicología produce no pueden ser directamente aplicados a la educación; no pueden servir de argumento directo para ella porque la psicología estudia el desarrollo cognitivo como un proceso natural, como un proceso espontáneo. Por tanto, no se puede aplicar directamente a la 
práctica pedagógica pues esta última, no es un proceso natural." 24 .

A pesar de lo expuesto y precisamente por no ser un proceso natural, la teoría de Piaget permite direccionarla hacia el aprendizaje significativo en oposición al repetitivo y memorístico, y también hacia el aprendizaje innovador producto de la exploración y el descubrimiento.

\section{Lev Vygotsky}

Vygotsky representa a la escuela rusa de psicología pero, a diferencia de Pavlov, que también la representa, nos legó la llamada visión "histórico-cultural”. Los postulados Vygotskianos, están siendo retomados fuertemente en la actualidad, pues su teoría representa una visión que destaca la importancia del ser social y por tanto de la relación comunicante entre los seres humanos, por ser la fuerza impulsadota del desarrollo cognitivo.

Han sido varios los aportes significativos realizados por Vygotsky, pues sus postulados "producen, curiosamente, un impacto a nivel de la psicología y a nivel de la educación. Tanto es así, que Vygotsky es hoy una figura central en la teoría moderna del currículum" 25 , planteó la necesidad de estudiar los procesos psicológicos superiores por ser considerados específicamente humanos. Pero uno de los aportes primordiales que realizó el autor en este campo, y que a mi juicio, si queremos construir reflexiones y propuestas que generen transformaciones educativas significativas, innovadoras y respetuosas del ser humano, no podemos obviar, es la denominada Zona de desarrollo próximo, que al decir de Prieto Castillo, es un "descubrimiento fundamental que ha cambiado la manera de concebir tanto la inteligencia, como el desarrollo y la educación"26. 
Constituye "el área en la que el niño no puede resolver solo el problema; pero, con la ayuda de un adulto o en colaboración con otro niño más avanzado lo puede hacer" 27.

Tryphon indica que "es la distancia entre el nivel evolutivo en acto (del niño), tal como lo determina la resolución independiente de problemas, y el nivel de desarrollo potencial, tal como se determina en la resolución de problemas con orientación adulta, o en colaboración con pares más capaces" 28 .

En este planteamiento de Vygotsky, se puede comprender que el conocimiento surge como aporte de la cultura, en la medida que la cultura será siempre la manifestación de un otro u otros que hacen sociedad y en relación con el momento histórico en que a cada ser humano le toca vivir.

Vygotsky señala que la zona de desarrollo próximo es la distancia que existe entre el nivel de desarrollo real y el desarrollo potencial, en el primero se manifiesta todo lo que el individuo hace sin ayuda y el segundo se alcanza con la intervención de un Otro que es quien le ayuda a dar el salto (cognitivo), es decir se convirtió en un mediador del conocimiento "Vygotsky sostenía que lo que los niños pueden hacer con la ayuda de otros es incluso más indicativo de su desarrollo mental de lo que pueden hacerlo solos" 29 .

El sujeto logra dar el salto cognitivo si es capaz de aprovechar en el mejor sentido de la palabra la ayuda que le brinda el otro, siempre y cuando este otro se encuentre mejor capacitado para ayudar a dar el salto, es decir para mediar y lograr que se produzca el conocimiento.

"A esta ayuda Vygotsky la llama mediación", siendo éste el punto clave de sus aportaciones, a partir de la cual propone un giro al trabajo pedagógico, pues cam- 
bia ciertas rotulaciones cognitivas que se han venido manejando típicamente en el campo educativo, por ejemplo: "no son capaces de aprender", "no dan más", "es incapaz", etc., pues lo que habría que reflexionar es si somos capaces de mediar. Así, la dificultad para dar el salto está en el agente de mediación quien debe encontrarse mejor capacitado; de lo contrario, no hay mediación y por tanto no hay salto.

"La tesis del desarrollo próximo, involucra un cambio radical en la psicología y en ciencias humanas; una concepción distinta de la inteligencia, una concepción distinta de la educación y una concepción distinta en lo que es desarrollo humano" 30 .

\section{Psicoanálisis}

Las ideas psicoanalíticas no se encuentran desencajadas del ámbito educativo como podría suponerse; para explicarlo me remitiré a la figura de Freud y a uno de sus argumentos centrales donde plantea que el psiquismo humano se desarrolla por la presión ejercida por la cultura en el individuo. "Presión ejercida por una cultura que se orienta fundamentalmente a una inhibición de las pulsiones sexuales y a una transformación de las pulsiones humanas en general, a partir de la influencia de las relaciones con otros y de las diversas instituciones culturales. Esto lleva a una transformación del psiquismo que, como veremos, sigue una trayectoria específica desde el punto de vista individual" 31 .

La educación se convierte en un factor importante para someter las fuerzas pulsionales al poder de la razón.

Así cuando nacemos, somos Ello puro, es decir prima en nosotros la búsqueda del placer, la necesidad de satisfacer nuestros impulsos agresivos y sexuales, que en 
favor de la convivencia social deberán ser reprimidos por la acción de las normas, reglas o leyes interiorizadas en cada sujeto, es decir, a través de la represión, mecanismo por el cual se gesta la patología. En este sentido la educación cumple un rol determinante, sobre todo si tomamos en cuenta que la educación formal y no-formal en nuestro contexto es altamente represiva, siendo fuente de neurosis, pues no permite el fortalecimiento del Yo y por tanto del Sentido de Realidad; sin embargo, hacia allá deberá apuntar la educación. "Como dice el autor, reforzar el Yo dentro del psiquismo implica un trabajo de cultura, lo que implica como resultado el desarrollo del intelecto, de la razón y, por ende de un dominio sobre los impulsos inconcientes" 32 .

La represión no hace más que atenuar las manifestaciones de las exigencias pulsionales, pero no las canaliza, de ahí que la educación tiene una función difícil, pues debe contribuir a la estructuración saludable de la personalidad de los sujetos, debe tender a fortalecer la capacidad de razonamiento, permitirle al sujeto decidir, reflexionar y actuar, en conexión con su realidad; es decir, una educación que promueva la reflexión y la crítica en oposición a una educación altamente represiva deberá conocer, cuándo, cuánto y cómo interiorizar la norma social.

\section{Psicología humanista}

El enfoque humanista surge como una tercera alternativa para comprender el comportamiento humano. Se opone a los dos referentes psicológicos anteriores a éste, como son: el conductismo y el psicoanálisis, por su visión y por considerar que poseen una visión reduccionista y determinista del comportamiento humano; así, en el primer caso, hacia la conducta y en el segundo hacia el inconsciente y el pasado. 
Tiene como punto de partida una visión positiva del ser humano, considera que su naturaleza es la bondad, la misma que se expresa o se anula de acuerdo a los contextos en los que los individuos nos desarrollamos; así, ambientes que ofrezcan condiciones psicológicas saludables, favorecerán la expresión de esa bondad, contextos desfavorables darán lugar a comportamientos opuestos a su naturaleza.

Son cinco los principios que rigen la visión humanista que fueron plantedos por Bugental (1963) y que permiten comprender las propuestas desde esta visión:

"1. En su condición de ser humano el hombre es, más las sumas de sus partes.

2. La existencia del hombre se consume en el seno de las interrelaciones psicosociales que establece.

3. Una característica esencial del hombre es su porción de vida consciente, lo que constituye la base para la comprensión de su existencia.

4. El hombre tiene capacidad de elegir y decidir con libertad desde los contenidos de su conciencia.

5. El hombre es intencional, viviendo orientado hacia metas, en función de razones, intereses, creencias y valores" 33 .

Es decir, la psicología humanista resalta que el ser humano es un ser integral, que se construye como persona en la interacción humana, consciente, con capacidad de decidir y elegir en libertad y orientado al crecimiento personal.

Estas características permiten visualizar al ser humano como constructor y actor, pues quien elige y decide en libertad está construyendo su proyecto de vida y es capaz de asumirlo con responsabilidad; a su vez, estas características tienen incidencia en el ambiente educativo, 
especialmente como base de las propuestas transformadoras y liberadoras de la educación.

\section{Carl Rogers}

Constituye una de las figuras más representativas de la psicología humanista llamada también "tercera fuerza", son reconocidos sus aportes en el ámbito educativo, en el año de 1969 publica el ensayo Libertad y creatividad en la educación, "donde se habla acerca del aprendizaje, pero no del aprendizaje pasivo, memorístico y mecánico, sino del aprendizaje vivencial, en el que se da una fuerte connotación de compromiso personal (cognoscitivo y afectivo), saturado de libertad y responsabilidad, completamente de espaldas a la tradicional instrucción enseñaza" 34 .

El análisis sobre la importancia del elemento afectivo en la relación profesor-estudiante es uno de sus principales aportes que se plasma en su planteamiento de la educación centrada en el estudiante, lo que permite identificar el giro que propone en el ámbito educativo al dar prioridad a la persona y no a los contenidos u otros aspectos, lo que no significa ignorarlos, pero prioriza sobre todo las relaciones humanas como base del proceso educativo lo que se puede evidenciar en el siguiente enunciado que realiza

Rogers citado por Hernández: "el aprendizaje que tiene lugar desde la nuca hacia arriba y que no involucra sentimiento o significación personal no tiene relevancia para la persona total" 35

La visión del ser humano como ser integral es trascendente para la educación, pues de alguna manera este enfoque propone que la educación no se reduzca al factor intelectual, social, cultural, sino que considere 
también la dimensión individual y personal, se opone a una educación que centre sus objetivos en la adaptación del sujeto a la sociedad, para trascender hacia una educación integral que le permita a la persona alcanzar la autorrealización.

Otro aporte en la teoría de Rogers y que se liga con la experiencia educativa, es el de auto concepto, el mismo que se construye también en el entorno sociocultural, específicamente en la relación interpersonal, en todo ser humano existe la necesidad de ser aceptados por los demás, aunque para lograrlo, muchas personas renuncian a su autenticidad, haciendo uso de lo que Rogers llama máscaras sociales "se suprimen las acciones y sentimientos que son inaceptables para los otros, que son importantes para la persona (los otros significativos) en lugar de utilizar las propias percepciones y sentimientos espontáneos como guías de conducta" 36 ; es decir, evidenciamos que somos aceptados en la medida en que dejamos de ser nosotros para ser lo que quieren de nosotros y esto genera la vivencia de la incongruencia lo que hace que el individuo cuestione su accionar, se incomode, no se acepte, lo que incide en la probabilidad de formar un sí mismo, o autoconcepto frágil y negativo.

En la formación del auto concepto intervienen dos aspectos fundamentales:

1. Lo que los otros dicen de mí; y,

2. La valoración que realizo de las consecuencias de mis actos y/o experiencias.

Rogers plantea la importancia de propiciar procesos educativos que se desarrollen en un marco de respeto, valoración personal, y de riqueza experiencial, que desarrolle la empatía, que implique aceptación incondiconal y promueva la autenticidad. 
"Rogers está más interesado en conseguir un individuo autorrealizado, con confianza, en sí y en el otro, que en aumentar el bagaje de conocimientos y en acceder al aprender a aprender y no a la instrucción tradicional" 37

Las propuestas realizadas por la visión humanista no dejan de ser interesantes, innovadoras y profundamente cálidas. Sería ilógico no aceptar incluso por sentido común el valor del respeto, de la autonomía, de la empatía en el proceso educativo; sin embargo, no podemos dejar de ser críticas y críticos frente a esta visión, pues no alcanza la buena intención para contribuir a una educación renovadora, afectiva pero crítica. Se requiere, insisto, posicionarse políticamente frente a ella.

No se trata de reducir el aporte de la psicología a las teorías citadas, pero sí constituyen grandes e influyentes visiones psicológicas que permiten comprender cómo la educación, en el amplio sentido del término, está íntimamente vinculada con el desarrollo integral de la persona, sea facilitándolo u obstaculizándolo, por tanto incide en el desarrollo cognitivo y la construcción de la personalidad, y esto exige entrar en el conocimiento psicológico para aportar a la reflexión de la educación desde una visión holística y crítica.

El introducirnos en el conocimiento de los enfoques psicológicos pretende que podamos reconocer el lugar de la psicología en la filosofía de la educación, a partir de identificar cómo las vivencias del proceso educativo penetran en el psiquismo y configuran la personalidad.

Inicié el presente artículo preguntado si era posible pensar, reflexionar y generar propuestas en la educación sin comprender el comportamiento desde una perspectiva científica del actor que posibilita el hecho educativo, "el ser humano", y concluyo esperando que lo 
expuesto, haya permitido visualizar la importancia del conocimiento de la dimensión psicológica para comprender las ventajas, desventajas, posibilidades y limitaciones que el acto educativo puede generar en ese ser humano y por tanto, la vinculación de la psicología con la filosofía de la educación.

\section{Notas:}

1 La sociedad refleja necesidades evidentes, que en ocasiones por ser tan cotidianas ya no incomodan, ya no molestan, ya no le movilizan al ser humano, tornándole un ser pasivo y conformista; es en estos hechos, donde propongo que habrá que crear o recrear necesidades, como las de vivir dignamente, combatir la corrupción, exigir el derecho a la educación, a manifestar nuestros afectos, etc.

2 Diselpidia.- la expresión extrema de la desesperanza y el sin sentido de la vida

3 REBELLATO, José Luis, En: "La globalización y su impacto educativo-cultural”. El nuevo horizonte posible, pág. 1

4 FROMM, Erich, Psicoanálisis de la sociedad contemporánea, Hacia una sociedad sana, 9na. Reimpresión, Ed. Lito Ediciones Olimpia S.A., México, 1971, pág. 25-26.

5 VASCONEZ, Belén, La construcción social del miedo, Ed. ABYAYALA, Serie Magister, Vol. 59, Quito, 2005, pág. 15.

6 REBELLATO, José Luis, En: "La globalización y su impacto educativo-cultural. El nuevo horizonte posible, pág.2.

7 FROMM, Erich, Psicoanálisis de la sociedad contemporánea, Hacia una sociedad sana, 9na. Reimpresión, Ed. Lito Ediciones Olimpia S.A., México, 1971, pág. 24

8 PRIETO CASTILLO, Daniel, Memorias del Seminario "en torno a la formación de educadores universitarios”,pág.20, Quito, 2005.

9 BARALDI, Clemenciam aprender: La aventura de soportar el equívoco, 3ra. Edición, Ed. HomoSapiens, 2002. pág. 47

10 Idem. Pág.43

11 Tómese en cuenta que hablo de teorías del aprendizaje, no teorías cognitivas.

12 HERNANDEZ, Pedro, Psicología de la educación, corrientes actuales y teorías aplicadas, Ed. TRILLAS, 1991, pág.97

13 Ibid, pág. 129 
14 Ibid,pág. 129

15 CRAIG,Crace y WOOLFOLK, Anita, Manual de psicología y desarrollo educativo, tomo III, Ed. Prentice-Hall Hispanoamericana, México, 1990, pág.54

16 Ibid, pág. 57

17 PRIETO CASTILLO, Daniel y MOLINA, Víctor, El aprendizaje en la universidad módulo II, cuarta edición, Mendoza - Argentina, 2003, pág. 72

18 CRAIG,Crace y WOOLFOLK, Anita, Manual de psicología y desarrollo educativo, tomo III, Ed Prentice-Hall Hispanoamericana, S.A MEXICO, pág. 57.

19 PRIETO CASTILLO, Daniel y MOLINA, Víctor, El aprendizaje en la universidad módulo II, cuarta edición, Mendoza - Argentina, 2003, pág. 72

20 bid. pág. 69

21 HERNANDEZ, Pedro, Psicología de la educación, corrientes actuales y teorías aplicadas, Ed. TRILLAS, 1991, pág.152

22 BARALDI, Clemenciam aprender: La aventura de soportor el equivoco, 3ra. Edición, Ed. Homo Sapiens, 2002. pág.43

23 HERNANDEZ, Pedro, Psicología de la educación, corrientes actuales y teorías aplicadas, Ed. TRILLAS, 1991, pág.161

24 PRIETO CASTILLO, Daniel y MOLINA, Víctor, El aprendizaje en la universidad módulo II, cuarta edición, Mendoza - Argentina, 2003, pág.75.

25 Idem. Pág. 76

26 Ibid.

27 CRAIG,Crace y WOOLFOLK, Anita, Manual de psicología y desarrollo educativo, tomo III, Ed Prentice-Hall Hispanoamericana, S.A MEXICO, pág. 73.

28 TRYPHON, Anastasia, Piaget-Vygotsky, La génesis social del pensamiento, Ed. Paidos Eucado, México, 1996, pág.192

29 TRYPHON, Anastasia, Piaget-Vygotsky, La génesis social del pensamiento, Ed. Paidos Eucador, México, 1996, pág.192

30 PRIETO CASTILLO, Daniel y MOLINA, Víctor, El aprendizaje en la universidad módulo II, cuarta edición, Mendoza - Argentina, 2003, pág.79.

31 PRIETO CASTILLO, Daniel y MOLINA, Víctor, El aprendizaje en la universidad módulo II, cuarta edición, Mendoza - Argentina, 2003, pág.79.

32 Ibid. Pág. 85 
33 SANCHEZ-BARRANCO RUIZ, Antonio, Historia de la psicología, sistemas, movimientos y escuelas, Ed. Pirámide, 1996, Madrid - España, pág. 408

34 Ibid. pág. 418

35 HERNANDEZ, Pedro, Psicología de la educación, corrientes actuales y teorías aplicadas, Ed. TRILLAS, 1991, pág.366

36 GROSS, Richard, Psicología, la ciencia de la mente y la conducta, Ed. El manual moderno, 1996, pág. 807.

37 SANCHEZ-BARRANCO RUIZ, Antonio, Historia de la psicología, sistemas, movimientos y escuelas, Ed. Pirámide, 1996, Madrid España, pág. 